10-1-2012

\title{
Perceptions of Feedback among Undergraduate and Postgraduate Students of Four Health Science Disciplines
}

Jenny Strong

The University of Queensland

Clair Hughes

The University of Queensland

Wayne Wilson

The University of Queensland

Wendy Arnott

The University of Queensland

Rosemary Isles

The University of Queensland

See next page for additional authors

Follow this and additional works at: https://nsuworks.nova.edu/ijahsp

Part of the Medicine and Health Sciences Commons

\section{Recommended Citation}

Strong J, Hughes C, Wilson W, Arnott W, Isles R, Bennison A. Perceptions of Feedback among Undergraduate and Postgraduate Students of Four Health Science Disciplines. The Internet Journal of Allied Health Sciences and Practice. 2012 Oct 01;10(4), Article 11.

This Manuscript is brought to you for free and open access by the College of Health Care Sciences at NSUWorks. It has been accepted for inclusion in Internet Journal of Allied Health Sciences and Practice by an authorized editor of NSUWorks. For more information, please contact nsuworks@nova.edu. 


\title{
Perceptions of Feedback among Undergraduate and Postgraduate Students of Four Health Science Disciplines
}

\begin{abstract}
Feedback is an important support for student learning. Yet data suggests that some students are often under-whelmed with the feedback they receive. Two factors potentially influencing this perception are entry level and type of health science program. To investigate this further, 492 undergraduate and postgraduate students from four health science disciplines (occupational therapy, physiotherapy, speech pathology and audiology) at a large Australian university were asked to complete a survey on the feedback that they had received during their studies. Students reported that they valued feedback with $93 \%$ seriously engaging with their feedback and $88 \%$ considering that feedback assisted their learning. However, different perceptions on some areas of feedback were reported by different groups. Postgraduate students had significantly ( $p<0.01$ to 0.0005 ) higher satisfaction with several aspects of feedback than undergraduate students, while audiology students reported significantly ( $p<0.05$ to 0.0001$)$ higher satisfaction levels than the other disciplinary groups. Fifty-eight percent of the students felt that feedback would be improved if it was more timely and if there was more of it, particularly in practical classes (55\%). Methods of improving the feedback provided to these students are discussed.
\end{abstract}

\section{Authors}

Jenny Strong, Clair Hughes, Wayne Wilson, Wendy Arnott, Rosemary Isles, and Anne Bennison 


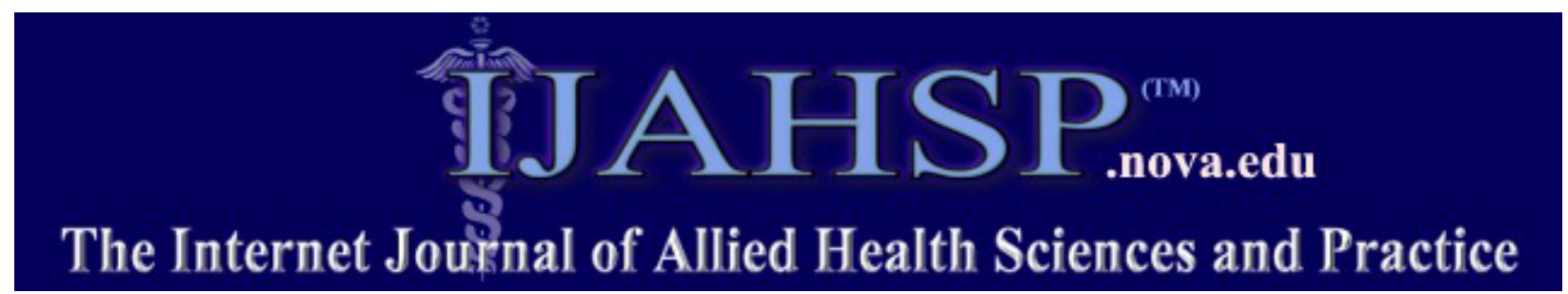

A Peer Reviewed Publication of the College of Health Care Sciences at Nova Southeastern University

Dedicated to allied health professional practice and education

http://ijahsp.nova.edu Vol. 10 No. 4 ISSN 1540-580X

\title{
Perceptions of Feedback Among Undergraduate and Postgraduate Students of Four Health Science Disciplines
}

\author{
Jenny Strong, $\mathrm{PhD}{ }^{1}$ \\ Clair Hughes, $\mathrm{PhD}^{2}$ \\ Wayne Wilson, $\mathrm{PhD}^{3}$ \\ Wendy Arnott, $\mathrm{PhD}^{4}$ \\ Rosemary Isles, MEd 5 \\ Anne Bennison, BEd 6
}

1. Professor of Occupational Therapy, The University of Queensland, Brisbane

2. Senior Lecturer, Tertiary Education Development Unit, The University of Queensland, Brisbane

3. Senior Lecturer in Audiology, School of Health \& Rehabilitation Sciences, The University of Queensland, Brisbane

4. Lecturer in Speech Pathology, School of Health \& Rehabilitation Sciences, The University of Queensland, Brisbane

5. Lecturer in Physiotherapy, School of Health \& Rehabilitation Sciences, The University of Queensland, Brisbane

6. Project Officer, School of Health \& Rehabilitation Sciences, The University of Queensland, Brisbane

Australia

CITATION: Strong J, Hughes C, Wilson W, Arnott W, Isles R, Bennison A. Perceptions of Feedback Among Undergraduate and Postgraduate Students of Four Health Science Disciplines. The Internet Journal of Allied Health Sciences and Practice. Oct 2012. Volume 10 Number 4.

\begin{abstract}
Feedback - information that assists students to bridge the gap between current and intended academic performance -- is an important support for student learning. Yet data suggests that some students are often under whelmed with the feedback they receive. Two factors potentially influencing this perception are entry level and type of health science program. To investigate this further, 492 undergraduate and postgraduate students from four health science disciplines (occupational therapy, physiotherapy, speech pathology and audiology) at a large Australian university were asked to complete a survey on the feedback that they had received during their studies. Students reported that they valued feedback with $93 \%$ seriously engaging with their feedback and $88 \%$ considering that feedback assisted their learning. However, different perceptions on some areas of feedback were reported by different groups. Postgraduate students had significantly $(p<0.01$ to 0.0005$)$ higher satisfaction with several aspects of feedback than undergraduate students, while audiology students reported significantly $(p<0.05$ to 0.0001$)$ higher satisfaction levels than the other disciplinary groups. Fifty-eight percent of the students felt that feedback would be improved if it was more timely and if there was more of it, particularly in practical classes (55\%). Methods of improving the feedback provided to these students are discussed.
\end{abstract}

\section{INTRODUCTION}

In the context of educating students in the health sciences, feedback refers to information describing a student's performance in a given activity that is intended to guide future performance in that same or a related activity. ${ }^{1}$ Feedback can be used to correct errors, reinforce concepts, diagnose problems, benchmark, and assist in the development of academic and clinical skills. ${ }^{4}$ When the focus of assessment is on learning, feedback can alert the students to how they can improve their performance with examples including improvements in interviewing skills, verbal and written histories, technical skills, resident teaching ability, and

(c) The Internet Journal of Allied Health Sciences and Practice, 2012 
physical examination skills. ${ }^{2-7}$ In this regard, feedback needs to indicate what "good" performance is, enable the student to attain that level of achievement, assist the student to self-assess, and encourage and motivate the student. 6

Despite the prima facie value of feedback, students often appear to have little opportunity to use feedback to update or improve their work, sometimes receiving feedback after their work has been graded or when subsequent assessment tasks are of a different nature.8,9 Taras, for example, found very little repetition of assessment types in six undergraduate programs at one English university, thus preventing students from using feedback to improve future performance. ${ }^{10}$ Furthermore, it has been observed that students frequently do not retrieve their marked assignments, thus rendering the feedback redundant.11,12 In a longitudinal study conducted over eight university business schools that included both undergraduate and graduate students, Price et al found that students and staff perceptions differed markedly on the purpose of feedback and its usefulness. ${ }^{13}$ Similarly, Gil et al showed that faculty members perceived that they provided effective feedback more often than students perceived that they received such feedback. ${ }^{14}$

A recent study by Ferguson has examined students' perceptions of what constitutes ideal feedback for teacher education students and explored the perceptions of a predominantly graduate entry level student group (465 graduates and 101 undergraduates). ${ }^{15}$ It was found that the views of the two student groups were similar. Feedback on positive aspects of work, as well as feedback to guide improvements, was seen as desirable, as was feedback received in a two week turn-around.

While the literature discussed above appears to argue for the value of feedback in the education of students in the health sciences, it also identifies several potential failure points in the provision of this feedback. Two of these points are entry level of the student and the type of health science program. With these factors in mind, staff at a large university in Queensland, Australia, sought to determine the attitudes of undergraduate and postgraduate students of audiology, occupational therapy, physiotherapy, and speech pathology towards the feedback they had received during their training at that university, with the aim of identifying ways of improving the quality of feedback provided to future students of these health sciences in this and similar universities in the region.

\section{METHODS}

Study Design

A single observation, non-experimental design was used in this study.

\section{Sample}

All students enrolled in the second and fourth year undergraduate programs (Occupational Therapy, Physiotherapy, and Speech Pathology) and second year Graduate Entry Masters programs (Occupational Therapy, Physiotherapy, and Speech Pathology and Audiology) were invited to participate in this study. The former were classified as undergraduates and the latter as postgraduates as they had already graduated from a previous bachelor's degree program and were now completing their training in their chosen health science by way of a postgraduate master's degree. The postgraduate students were, on average, three years older than the undergraduate students.

\section{Instrument}

An assessment questionnaire was designed with the assistance of the University's Teaching and Educational Development Institute. It was based on instruments used in previous studies and the university's existing student satisfaction surveys. ${ }^{16}$ The questionnaire investigated students' experiences of assessment and feedback in the non-clinical courses they had undertaken in their programs. Students were asked to select from a series of statements the one that most accurately reflected their belief about the purpose of assessment. Thirty-five questions then canvassed students' views on Assessment \& Learning, Nature \& Quality of Assessment Tasks, and Feedback. Only the items related to feedback will be described here.

The Feedback items asked students about the advice they would give to academic staff who wanted to improve the quality of feedback given to students. Students were then asked their opinions on nine specific feedback items, which used a Likert scale where scores of $1=$ strongly disagree, and scores of $5=$ strongly agree. Measures of the amount of feedback, its timeliness and its quality, were considered as proxies of its effectiveness, notwithstanding the simplistic nature of this assumption. ${ }^{4}$

\section{Procedure}

The project was cleared by the relevant university institutional ethics committee prior to commencement. A research officer (who was not involved in the teaching programs in the school) gave all students the questionnaire, participant information letter, and consent form during an introductory lecture at the beginning of the teaching year. The research officer described the purpose of the survey, and those who gave written informed consent then completed the questionnaire during the allocated class time. 
Participation was voluntary with questionnaires returned to the research officer with no identifying features other than program type and year level.

\section{Data Analysis}

The response categories to the feedback items were collapsed to simplify analysis and presentation of results. "Strongly Agreed" and "Agreed" categories were combined to indicate a positive response to the statements and the "Undecided," "Disagree," and "Strongly Disagree" categories were combined to indicate a negative response. The "Undecided" category was included as a negative response to ensure that the responses classified as positive were clearly positive. The conservative nature of this decision was noted.

Pearson chi-square analyses were used to examine significant differences between feedback and program type (undergraduate versus postgraduate) and feedback across and between disciplines for undergraduates and postgraduates combined as well as for undergraduates only and postgraduates only.

\section{RESULTS}

Questionnaires were distributed to all students who attended the nominated lecture in each program. As attendance records were not taken at lectures, the response rates were based on the number of students enrolled in each program on the first day of the teaching year. The actual response rates may be slightly higher than those reported, as not all enrolled students may have been present. The overall response rate for all students was $75.5 \%$ (492/652), with similar response rates obtained for undergraduate $(76.0 \%, 399 / 525)$ and postgraduate $(73.2 \%, 93 / 127)$ students. The response rates for each discipline for its undergraduate students, its postgraduate students and overall (respectively) were as follows: audiology - no undergraduate option, $100 \%$ post-graduates (39/39) and $100 \%$ overall (39/39); occupational therapy - $94.8 \%$ undergraduates (163/172), $90.5 \%$ post-graduates (19/21), and $94.3 \%$ overall (182/193); physiotherapy - $60.4 \%$ undergraduates (131/217), $23.1 \%$ post-graduates (9/39), and $54.7 \%$ overall (140/256); and speech pathology $-77.2 \%$ undergraduates (105/136), $92.9 \%$ post-graduates (26/28), and $79.9 \%$ overall $(131 / 164)$.

The overall results, as well as those for undergraduate and postgraduate students, are expressed as a percentage of positive responses as shown in Tables 1 and 2 . Almost $93 \%$ of the students indicated that they carefully considered the feedback provided to them on assessment, $88.2 \%$ of students felt that the feedback they received on assessment tasks facilitated their learning, while $92.7 \%$ reported that the verbal feedback they received in practical sessions aided their learning. However, only $53.1 \%$ of students thought that the overall quality of feedback in their program was high. Less than half thought that feedback was prompt (41.6\%) and that there was enough feedback during practical sessions (44.5\%). Less than one fifth (18.2\%) reported that they only read the marks.

Table 1. Overall Percentage of Students Responding Positively to Statements on Feedback

\begin{tabular}{|l|c|}
\hline Statement & Overall \% \\
\hline Feedback on assessment tasks facilitates my learning & $88.2 \%$ \\
\hline Feedback on my work has been prompt & $41.6 \%$ \\
\hline I would learn more if I received more feedback & $88.7 \%$ \\
\hline I read the feedback carefully and try to understand what it is saying. & $92.9 \%$ \\
\hline The feedback prompts me to go back over material covered earlier & $65.0 \%$ \\
\hline I tend only to read the grades or marks. & $18.2 \%$ \\
\hline Verbal feedback in practical sessions assists my learning & $92.7 \%$ \\
\hline There is enough verbal feedback during practical sessions. & $44.5 \%$ \\
\hline The overall quality of feedback in this program is high & $53.1 \%$ \\
\hline
\end{tabular}


Table 2. Percentage of Students Responding Positively to Statements on Feedback by Program Type

\begin{tabular}{|l|c|c|c|c|}
\hline Statement & UG & PG & $\chi^{2^{*}}$ & $P$ \\
\hline Feedback on assessment tasks facilitates my learning & $87.7 \%$ & $90.1 \%$ & 0.41 & 0.52 \\
\hline Feedback on my work has been prompt & $38.6 \%$ & $54.3 \%$ & 7.33 & $<0.01$ \\
\hline I would learn more if I received more feedback & $88.9 \%$ & $87.5 \%$ & 0.10 & 0.75 \\
\hline I read the feedback carefully and try to understand what it is saying. & $92.4 \%$ & $95.1 \%$ & 0.76 & 0.38 \\
\hline The feedback prompts me to go back over material covered earlier & $60.9 \%$ & $82.7 \%$ & 14.24 & $<0.0005$ \\
\hline I tend only to read the grades or marks. & $18.7 \%$ & $16.0 \%$ & 0.37 & 0.54 \\
\hline Verbal feedback in practical sessions assists my learning & $93.0 \%$ & $91.4 \%$ & 0.23 & 0.63 \\
\hline There is enough verbal feedback during practical sessions. & $44.0 \%$ & $46.3 \%$ & 0.23 & 0.63 \\
\hline The overall quality of feedback in this program is high & $49.5 \%$ & $69.1 \%$ & 10.82 & $<0.005$ \\
\hline
\end{tabular}

The relationship between undergraduate and postgraduate program type and student responses was analysed with chi-square tests of the frequency distributions. Significant differences were found between undergraduate and postgraduate students for three of the nine feedback statements (see Table 2). The postgraduate students were more likely than the undergraduate students to agree with the statements that feedback was prompt, that they used the feedback to go back over material covered earlier, and that the overall quality of the feedback in their programs was high.

The relationship between discipline and student responses to the statements on feedback was analysed by conducting chisquare tests of the frequency distributions for both undergraduate and postgraduate students. Significant differences were found for five of the nine feedback statements (see Table 3). The four disciplinary groups had similar responses on feedback facilitating learning, verbal feedback in practical sessions assists learning, learning would increase if more feedback was given and tending to only read the grades or marks. On the five items that had significant differences, the Audiology students were most positive for all statements.

Table 3. Percentage of All Students Responding Positively to Statements on Feedback by Discipline

\begin{tabular}{|l|c|c|c|c|c|c|}
\hline Statement & PT & OT & SP & AUD & $\chi^{2^{*}}$ & $P$ \\
\hline Feedback on assessment tasks facilitates my learning. & $86.3 \%$ & $88.6 \%$ & $88.3 \%$ & $93.1 \%$ & 1.09 & 0.78 \\
\hline Feedback on my work has been prompt. & $31.6 \%$ & $40.9 \%$ & $43.0 \%$ & $79.3 \%$ & 21.91 & $<0.0001$ \\
\hline I would learn more if I received more feedback & $88.0 \%$ & $89.8 \%$ & $89.1 \%$ & $82.1 \%$ & 1.48 & 0.69 \\
\hline $\begin{array}{l}\text { I read the feedback carefully and try to understand what it is } \\
\text { saying. }\end{array}$ & $87.2 \%$ & $94.9 \%$ & $94.5 \%$ & $96.6 \%$ & 7.95 & $<0.05$ \\
\hline $\begin{array}{l}\text { The feedback prompts me to go back over material covered } \\
\text { earlier }\end{array}$ & $67.5 \%$ & $56.6 \%$ & $69.3 \%$ & $86.2 \%$ & 12.54 & $<0.01$ \\
\hline I tend only to read the grades or marks. & $24.1 \%$ & $17.6 \%$ & $15.3 \%$ & $10.3 \%$ & 4.68 & 0.20 \\
\hline Verbal feedback in practical sessions assists my learning & $97.4 \%$ & $91.2 \%$ & $91.8 \%$ & $86.2 \%$ & 6.41 & 0.09 \\
\hline There is enough verbal feedback during practical sessions. & $35.3 \%$ & $43.0 \%$ & $52.1 \%$ & $58.6 \%$ & 9.21 & $<0.05$ \\
\hline The overall quality of feedback in this program is high & $45.2 \%$ & $48.9 \%$ & $61.1 \%$ & $75.9 \%$ & 13.42 & $<0.005$ \\
\hline
\end{tabular}

Differences in responses of the four disciplinary groups were further analysed in two parts, undergraduate and postgraduate, because there are no undergraduate Audiology students and because differences between the responses for undergraduate and postgraduate students had already been identified. The percentages of positive responses for undergraduate occupational therapy, physiotherapy, and speech pathology students are shown in Table 4. Only two of the assessment items had significantly different responses between the undergraduate groups, these being the item, "I read the feedback carefully and try to understand what it is saying" and "There is enough verbal feedback during practical sessions." The undergraduate physiotherapy students' scores on reading feedback carefully were lower than the scores for occupational therapy and speech pathology. With respect to the item on receiving enough verbal feedback during practical sessions, the speech pathology students scored highest, then the occupational therapy students, followed by the physiotherapy students. 
Table 4. Percentage of Undergraduate Students Responding Positively to Statements on Feedback by Discipline

\begin{tabular}{|l|c|c|c|c|c|}
\hline Statement & PT & OT & SP & $\chi^{2^{*}}$ & $P$ \\
\hline Feedback on assessment tasks facilitates my learning & $86.2 \%$ & $88.5 \%$ & $88.2 \%$ & 0.33 & 0.85 \\
\hline Feedback on my work has been prompt & $32.1 \%$ & $40.1 \%$ & $43.1 \%$ & 2.98 & 0.23 \\
\hline I would learn more if I received more feedback & $89.0 \%$ & $90.4 \%$ & $86.4 \%$ & 1.02 & 0.60 \\
\hline I read the feedback carefully and try to understand what it is saying. & $87.2 \%$ & $94.9 \%$ & $94.1 \%$ & 6.09 & $<0.05$ \\
\hline The feedback prompts me to go back over material covered earlier & $66.1 \%$ & $54.5 \%$ & $65.3 \%$ & 4.75 & 0.09 \\
\hline I tend only to read the grades or marks. & $24.1 \%$ & $16.6 \%$ & $16.3 \%$ & 2.88 & 0.24 \\
\hline Verbal feedback in practical sessions assists my learning & $97.2 \%$ & $91.4 \%$ & $90.6 \%$ & 4.44 & 0.11 \\
\hline There is enough verbal feedback during practical sessions. & $35.2 \%$ & $42.2 \%$ & $57.0 \%$ & 9.97 & $<0.01$ \\
\hline The overall quality of feedback in this program is high & $43.9 \%$ & $48.4 \%$ & $57.0 \%$ & 3.66 & 0.16 \\
\hline
\end{tabular}

The percentages of positive responses for postgraduate students are shown in Table 5. The only item that was significantly different across the four postgraduate student groups was the item on the promptness of feedback. Visual inspection of the scores indicated that audiology students were most positive $(79.3 \%)$, followed by occupational therapy students $(47.4 \%)$, speech pathology students $(42.3 \%)$, and then physiotherapy students $(25.0 \%)$. These results must be interpreted with caution however, as some of the cell counts were small.

Table 5. Percentage of Postgraduate Students Responding Positively to Statements on Feedback by Discipline

\begin{tabular}{|l|c|c|c|c|c|c|}
\hline Statement & PT & OT & SP & AUD & $\chi^{2^{*}}$ & $P$ \\
\hline Feedback on assessment tasks facilitates my learning. & $87.5 \%$ & $89.5 \%$ & $88.5 \%$ & $93.1 \%$ & 0.44 & 0.93 \\
\hline Feedback on my work has been prompt. & $25.0 \%$ & $47.4 \%$ & $42.3 \%$ & $79.3 \%$ & 11.97 & $<0.01$ \\
\hline I would learn more if I received more feedback. & $75.0 \%$ & $84.2 \%$ & $100.0 \%$ & $82.1 \%$ & 5.84 & 0.12 \\
\hline $\begin{array}{l}\text { I read the feedback carefully and try to understand what it is } \\
\text { saying. }\end{array}$ & $87.5 \%$ & $94.7 \%$ & $96.2 \%$ & $96.6 \%$ & 1.20 & 0.75 \\
\hline $\begin{array}{l}\text { The feedback prompts me to go back over material covered } \\
\text { earlier. }\end{array}$ & $87.5 \%$ & $73.7 \%$ & $84.6 \%$ & $86.2 \%$ & 1.54 & 0.67 \\
\hline I tend only to read the grades or marks. & $25.0 \%$ & $26.3 \%$ & $11.5 \%$ & $10.3 \%$ & 3.08 & 0.38 \\
\hline Verbal feedback in practical sessions assists my learning. & $100.0 \%$ & $89.5 \%$ & $96.2 \%$ & $86.2 \%$ & 2.60 & 0.46 \\
\hline There is enough verbal feedback during practical sessions. & $37.5 \%$ & $50.0 \%$ & $34.6 \%$ & $58.6 \%$ & 3.53 & 0.32 \\
\hline The overall quality of feedback in this program is high. & $62.5 \%$ & $52.6 \%$ & $76.9 \%$ & $75.9 \%$ & 3.97 & 0.27 \\
\hline
\end{tabular}

The responses to the open-ended questions given by the students were then reviewed. Many students stated that feedback should be given both when things needed to improve and when they were correct. As one undergraduate student suggested "Offer advice to everyone and not just those they think require more help. Everyone is learning. Everyone makes mistakes and needs to know if they are doing the right or the wrong thing." A postgraduate student suggested "write feedback even when the assessment is very good so the student can understand what they are doing right."

The student responses also indicated how they wanted to use feedback to help them learn. This view was exemplified by the student who wrote: "Provide more explanation when errors are highlighted. If a general trend exists, where a number of students make similar errors, possibly revisit this particular topic in lecture format." Others wanted feedback to be "increased [in] regularity and specificity," and "to be as close as possible to the event/assessment to be really valuable."

\section{DISCUSSION}

The undergraduate and postgraduate students sampled from the audiology (postgraduate only), occupational Therapy, physiotherapy, and speech pathology programs valued the feedback they received on their assessment tasks, and considered that they used such feedback to facilitate their learning. It is possible that the students were providing platitudes to staff (as they had yet to graduate from their programs), and may have told staff what they wanted to hear. However, as the data were collected anonymously by a research officer not associated with the teaching and assessment tasks in the school, it is hoped that students felt sufficiently comfortable to provide accurate perceptions. Further, students also provided less than positive perceptions about some aspects of feedback. Over half indicated that they wanted more timely feedback, almost half wanted feedback of higher quality. While students valued practical sessions as being important learning activities, they reported an inadequate amount of feedback during these practical sessions. 
Additionally, differences emerged between the entry level of the student and the type of health science program. These findings will now be considered in turn, followed by a discussion of methods of improving the feedback provided to these students.

\section{Differences by Entry Level of Student}

The finding that more postgraduate than undergraduate students felt feedback was prompt and of high quality, and that this prompted them to go back over material they had learned earlier, was noteworthy given that the postgraduate students typically provide lower overall scores on course evaluations compared to undergraduate students (unpublished institutional data). Possible reasons for greater satisfaction of postgraduate students may be their increased maturity or more practice at recognising and responding to University feedback. It may also have been due to cohort effects, where the postgraduate students were part of a 3-semester-a-year program where they became a cohesive group. Despite sharing many core classes and activities with the undergraduate students, the postgraduate students had different tutorial groups and some different learning experiences. These findings suggest that staff need to better signpost feedback, particularly for students in undergraduate programs who may not be aware of the full range of activities that constitute feedback (e.g. they may think feedback is limited to written comments about their performance specifically). Our findings were different from those of Ferguson, who found no difference between postgraduate and undergraduate students' views on feedback. ${ }^{15}$ However, his study looked at ideal feedback, whereas ours looked at actual feedback.

\section{Differences by Type of Health Science Program}

The finding that more audiology students responded positively to feedback (high quality, prompt and of sufficient quantity during practical classes, reading it carefully, and using it to review previously learned material) are most likely due to their being a small postgraduate group taught by academic staff not involved in a corresponding undergraduate program. Alternatively, these differences might reflect the post-graduate nature of the group only rather than its position in the discipline of audiology. This is suggested by the single significant difference found between the four disciplines when comparing them at the post-graduate level only (although these comparisons must be treated with caution due to the lower sample sizes).

\section{Methods of Improving Feedback Timely Feedback}

Over half the students in this study indicated that timeliness of feedback is of high priority. The importance of timely feedback has been widely acknowledged with an old observation made by Chickering and Gamson remaining pertinent: "... assessment without timely feedback contributes little to learning."17-19 Parkin et al reported that the longer the delay in receiving feedback, the less relevant such feedback is for the student. ${ }^{20}$ However, the issue of feedback timeliness is one with which universities continue to grapple, especially in relation to resource constraints. ${ }^{13}$ One method of providing instant and formative feedback that is being used more is the audience response system (ARS). ${ }^{21,22}$ These tools, commonly called clickers, provide real-time feedback that is especially helpful in large classes and are now being trialled in schools including the school involved in the present study. $22,23,24$

Other ideas on ways to enhance feedback opportunities without increasing teaching costs that are especially important for large classes can be gained from the Re-Engineering Assessment Practices (REAP) project.18 This project, while focusing on large first year courses, found the use of on-line group tasks and discussion boards and less direct lecture time was associated with increased exam performance and improved student satisfaction.

\section{Feedback Quality}

The finding that over half the students in this study wanted feedback of a higher quality raises the question, what exactly is quality feedback? Feedback from our students and others in studies such as those by Ferguson et al and Price et al indicate that feedback should provide students with a means of improving their performance. ${ }^{13,15}$ When errors were found in assessment pieces, explanations should indicate to students what the error was, and why it was an error. An assessment piece with a series of "ticks," isolated words such as "good," or grammatical corrections and a final grade provides inadequate feedback to students. 18,25 Sendzuik has described an approach where tutors provide written feedback on assignments and return them to the students who are then asked to provide a grade for themselves. ${ }^{11}$ The staff and students then compare grades. This process, where students need to self-critique their work and discuss variance with staff, has made students actively engage with the feedback that has been given.

\section{Feedback in Practical Classes}

While our respondents valued the feedback they received in their practical classes, they indicated that they wanted more. Such an indication is mitigated by resource constraints that work against ideal staff-student ratios, particularly in small practical classes where skill acquisition is critical. Skills required by students in the four health science programs included in this study cover a 
broad spectrum from cervical mobilisations, to hand splinting, to operating audiometric equipment, to perceptual voice analysis. While the use of simulated patients has been advanced across all of these disciplines, hands on experience remains the gold standard. ${ }^{26}$ Blended approaches to learning, such as that used by Dantas and Kemm, the use of DVD simulations, and real time feedback using iPads are worthy of further investigation. ${ }^{27,28}$

\section{CONCLUSIONS}

Of 492 undergraduate and postgraduate students of occupational therapy, physiotherapy, speech pathology, and audiology, 93\% reported they seriously engaged with the feedback they received and $88 \%$ reported the feedback assisted their learning. Differences were noted by type of student and health science, with postgraduate students reporting significantly ( $p<0.01$ to $0.0005)$ higher satisfaction with several aspects of feedback, and audiology students reporting significantly ( $p<0.05$ to 0.0001$)$ higher satisfaction levels. Methods of improving feedback were discussed, including options such as the audience response system (ARS), on-line group tasks, discussion boards and, student self-critique.

\section{ACKNOWLEDGEMENTS}

This study was supported by a university Strategic Teaching and Learning Grant.

\section{REFERENCES}

1. Ende J. Feedback in clinical medical education. JAMA. 1983;250(6):777-781.[PMID 6876333]

2. Verby JE. The Audiovisual Interview: a New Tool in Medical Education. JAMA. 1976;236(21):2413-4. [PMID 62066]

3. Scheidt PC, Lazoritz S, Ebbeling WL, Figelman AR, Moessner H, Singer J. Evaluation of System Providing Feedback To Students on Videotaped Patient Encounters. J Med Education. 1986;61(7):585-90. [PMID 3723570]

4. Kardash K, Tesler MJ. Videotape Feedback in Teaching Laryngoscopy. Can J Anaesthesia. 1997;44(1):54-8. [PMID 8988825]

5. Barth RJ Jr, Rowland-Morin PA, Mott LA, Burchard KW. Communication effectiveness training improves surgical resident teaching ability. J Am Coll Surg.1997;185(6):516-9. [PMID 9404872]

6. Sestini P, Rezoni E, Rossi M, Boltramin V, Vaqliasindi M. Multimedia presentation of lung sounds as a learning aid for medical students. European Respiratory Journal. 1995;8(5):783-8. [PMID 7544742]

7. Paul S, Dawson KP, Lanphear JH, Cheema MY. Video recording feedback: a feasible and effective approach to teaching history-taking and Physical examination skills in undergraduate paediatric medicine. Med Educ. 1998;32(3):332-6. [PMID 9743791]

8. Westberg J, Jason H. Providing Constructive Feedback. A CIS guidebook for Health Professions Teachers. Boulder, Colorado: (Centre for Instructional Support): Johnson Printing; 1991.

9. Menon SP, Kalishman S. Student Assessment. Academic Med. 1998;7399 Suppl):S46-54. [PMID 9759118]

10. Taras M. Do unto others or not: equity in feedback for undergraduates. Assess Eval Higher Educ. 2006;31:365-77.

11. Sendziuk P. Sink or swim? Improving student learning through feedback and self-assessment. Int J Teach Learn Higher Educ. 2010;22:320-30.

12. Sinclair HK, Cleland JA. Undergraduate medical students: who seeks formative feedback? Medic Educ. 2007;41(6):580-2. [PMID 17518838]

13. Price M, Handley K, Millar J, O'Donovan B. Feedback: all that effort, but what is the effect? Assess Eval Higher Educ. 2010;35:277-89.

14. Gil DH, Heins M, Jones PB. Perceptions of medical school faculty members and students on clinical clerkship feedback. $J$ Med Education. 1984;59(11 Pt 1):856-64. \{PMID 6492102]

15. Ferguson P. Student perceptions of quality feedback in teacher education. Assess Eval Higher Educ. 2011;36:51-62.

16. Brown E, Gibbs G, Glover C. Evaluation tools for investigating the impact of assessment regimes on student learning. Bioscience Education. 2003;2:5.

17. Gibbs G, Simpson C. Conditions under which assessment supports students' learning. Learn Teach Higher Educ. 2004;1:131.

18. Nicol D. Assessment for learner self-regulation: enhancing achievement in the first year learning technologies. AssessEvalHigher Educ. 2009;34:335-52.

19. Chickering A, Gamson Z. Seven principles for good practice in undergraduate education. The American Assoc Higher Educ Bull. 1987;39:3-7.

20. Parkin H, Hepplestone S, Holden G, Irwin B, Thorpe L. A role for technology in enhancing students' engagement with feedback. Assess Eval Higher Educ. 2011;36:125-36.

21. Stull JC, Varnum SJ, Ducette J, Schiller J, Bernacki M. The many faces of formative assessment. Int J Teach Learn Higher Educ. 2011;23:30-9. 
22. Collins LJ. Livening up the classroom: using audience response systems to promote active learning. Medic Ref Servic Quart. 2007;26(1):81-8. \{PMID 17210552]

23. Kaneshiro KN, Emmett TW, London SK, Ralston R, Richwine MW, Skopelja EN, Brahmi FA, Whipple E. Use of an audience response system in an evidence-based mini-curriculum. Med Ref Serv Q. 2008;27(3):284-301. [PMID 19042709]

24. Lim A, Rodger S. Use of formative assessment to enhance learning. Focus Health Profess Educ: Multidisc J. 2010;12:30-3.

25. Nicol D, Macfarlane-Dick D. Formative assessment and self-regulated learning: a model and seven principles of good feedback practice. J Contin Educ Health Profess. 2006;31:199-216.

26. Wilson WJ, Hill A, Hughes J, Sher A, Laplante-Levesque A. Student audiologists' impressions of a simulation training program. Aust New Zeal J Audiol. 2010;32:19-30.

27. Dantas AM, Kemm RE. A blended approach to active learning in a physiology laboratory-based subject facilitated by an elearning component. Advan Physiol Educ. 2008;32(1):65-75. [PMID 18334571]

28. Williams B, Brown T, Scholes R, French J, Archer F. Can interdisciplinary clinical DVD simulations transform clinical fieldwork education for paramedic, Occupational therapy, physiotherapy, and nursing students? J Allied Health. 2010;39(1):3-10. [PMID 20217001]

\section{KEY TERMS}

Feedback, Student Learning, Health Sciences, Student Perceptions 